\title{
ON SCIENTIFIC STATUS AND PRACTICAL SIGNIFICANCE OF ONE PSYCHOLOGYCAL THEORY
}

\author{
Andrei I. Podolskij \\ Lomonosov Moscow State University \\ Moscow
}

Since the late 1950s, a significant number of authors tried to use Galperin's approach (which is well-known as the "Theory of planned stage-by-stage formation of mental actions", or the PSFMA Theory) to improve schooling processes and results. Looking back at the more than fifty-year history of Galperin's approach, one may note that the 1960s and the early 1970s were the periods of the great optimism concerning effectiveness and efficiency of its practical application. It seemed possible to transform radically the way and the traditional results of learning/teaching process. To compare the 60s-70s and the 80s-90s publications one could easily discover a significant decrease of a wave of optimism concerning the PSFMA's application. Besides the obvious social-economic and social-psychological reasons there exists a methodological reason concerning the ways and means of the Galperin's approach use. Historically, the substantial pedagogical results of planned stage-by-stage formation of mental actions first came to the fore. However, the proponents' enthusiasm about really unusual and hopeful results had a reverse side: it led to the serious misunderstanding of the status of Galperin's approach and transformed the last to some absolute knowledge like a sort of "philosophers' stone". The successful application of the statements of PSFMA does not mean a literal reproduction of some abstract general procedure, but a creative design of a system of necessary and sufficient psychological conditions adapted to a concrete schooling situation. The elaboration of such a procedure occupies an intermediate position between the fundamental psychological knowledge and the real process of schooling. The three-model system is considered to bridge a gap between the fundamental knowledge introduced by Galperin and the real circumstances of learning/teaching situation.

Keywords: internalization, stage-by-stage formation of mental actions, human action properties, psychological, psychological-pedagogical, and technological models of the instruction situation, formation of attentiveness.

Since the late 1950s, a significant number of authors (both researchers and practicians) tried to use Galperin's approach (which is wellknown as The Theory of Planned Stage-By-Stage Formation of Mental 
Actions, or the PSFMA Theory) to improve schooling processes and results. Studies concerned the very different kinds and types of schools (primary, secondary, vocational, special schools). Subjects (learners) were ordinary, disabled, and gifted children of different ages (from 5 to 18) and adults. Specific domains were also very different: writing and arithmetic, native and foreign languages, math, scientific and humanitarian disciplines, drawing, music, physical training. At last, psychologically heterogeneous structures were the objects of planned stage-by-stage formation: separate specific domain mental actions and connected with them concepts and representations; groups and systems of actions and concepts; actions that underlie cognitive as well as metacognitive strategies and heuristics.

Looking back at the fifty-year history of Galperin's approach, one may note that the 1960s and early 1970s were the periods of the great optimism concerning effectiveness and efficiency of its practical application. Indeed, it seemed to be possible to transform radically the way and the traditional results of the learning/teaching process. As it has been convincingly demonstrated by hundreds of experimental and applied studies, the whole set of main objectives that any schooling is aimed at could be fulfilled: (a) it is ensured the guaranteed acquisition of the educational course practically by all the learners (all, of course, who have the necessary level of preliminary needed knowledge and skills) without the prolonging (sometimes - even with reducing) of the time allocated to it, and practically without any additional costs; (b) the division into the acquisition of knowledge and its application is minimized or even disappears; (c) the learners acquire abilities to transfer to a new situation: not only knowledge and skills are being formed, but also the way of acquiring; (d) the learners get more and more interested in the very processes of acquiring knowledge and in knowledge itself, because they are aware of the newly formed abilities (Galperin, 1989a; 1989b; Talyzina, 1987).

However, to compare the 60s-70s and 80s-90s publications one could easily discover a significant decrease of a wave of optimism concerning the PSFMA's application. Moreover, anyone being familiar with the current situation of school education can hardly discover the PSFMA's really extensive practical applications in contemporary schools as well as in schools of the nearest past. Of course, there were and there are a lot of interesting experiences in different parts of Russia and outside of it, which demonstrate the successes, failures and problems of the PSFMA's practical usage; however a scale of the usage is rather limited.

Besides the obvious social-economic and social-psychological reasons there exists one more reason of a methodological nature concerning the ways and means of the Galperin's approach use. Historically, it has been established that in most psychological research conducted along the lines of the approach discussed, the substantial pedagogical results of planned stage-by-stage formation of mental actions first came to the fore. However the proponents' enthusiasm about really unusual and hopeful results had a reverse side: it led to the serious misunderstanding of the status of Galperin's approach. Sometimes the approach is interpreted not as a general description of laws and regularities which try to explain the dynamics and results of human mental activity formation, but rather as a set of technologies and prescriptions how to teach. Indeed, such an interpretation distorts the reality and transforms the approach to some "absolute" knowledge like a sort of "philosophers" stone".

One should not forget that any scientific research ("pure" scientific or practically oriented study) is always based on a system of abstractions accepted. A direct use of research methods, created on the basis of such abstractions, has a number of fundamental restrictions. High results are never preserved in practical teaching if the circumstances that were abstracted from the course of an experimental formative procedure come to the fore in an actual situation. It is necessary to consider first what Galperin's approach is about. On the one hand this approach is the continuation of a trend in developmental and learning psychology that was started by Vygotsky (1978), but at the same time it also represents the following original parts: (a) issues on nature of human mental life, (b) its coming into existence and development in the context of philogenetical, anthropogenetical and ontogenetical processes, (c) the system of psychological conditions which enables knowledge and skills formation with the desired and prescribed outcomes.

According to Galperin, human (mental) action is described as a functional structure formed in one's lifetime and aimed at structuring of various problem situations the human being encounters; one plans and regulates the activity by means of socially established patterns, standards and evaluations. Such meaningful structuring, planning and regulating (which also includes control and correction of the previous three) 
has been called "orienting activity" ("orientation", "orientating function" and some other similar and synonymous expressions are met in the earlier works of Galperin). Mental action (as well as mental, or ideational, orienting part of any human action) can and should be considered as a result of the complex multimodal transformation of initially external processes performed by means of certain tools, thus being the result of internalization (Galperin, 1967; 1989b).

Any human action, reflecting human being needs as well as appropriating objective situation demands and conditions, may be characterized by a set of primary and secondary properties. Primary properties are: 1. Composition of action's objective content. 2. Extent of differentiation of problem situation essential elements from inessential. 3. Level of action performance, or level of its internalization. 4. "Energetic" (speed and enforcement) parameters. Secondary properties are: 1. Reasonability. 2. Generalization. 3. Consciousness. 4. Criticism. Secondary properties result from definite combinations of primary properties. Both groups of properties represent societal estimated and evaluated qualities of human activities and may refer to any sort of individual or collective, material or ideal, learning or labor, play or creative activity.

Final indicators of those properties characterize the action formed and internalized. They are considered to be the direct outcomes of action formation conditions. To have such a set of conditions which regularly and systematically ensure and guarantee an achievement of prescribed, desired properties of action, means to have a planned formation of (mental) action and, accordingly, a set (or, more correctly, a system) of psychological conditions of planned, stage-by-stage formation of mental actions, or a system of PSFMA.

This system includes four subsystems: (1) conditions for provision of adequate motivation for the subject mastery of the action; (2) conditions for the formation of necessary orientation basis of action; (3) conditions for consecutive transformations of the intermediate forms of action and for the end-transformation into the mental plan; (4) conditions for cultivating, or "refining through practice", action's desired properties (Galperin, 1989a; 1989b; 1992b). Each subsystem contains a detailed description of interconnected psychological conditions, which concern the motivational and operational spheres of human activity. Thus, the first subsystem makes explicit a number of links and connections between learning motivation and the dynamics of internalization processes. The
Second subsystem contains a description of hierarchically organized components of the action that offers a "framework" for the formation of action. These are representations of final products of action and its intermediate products, of a general plan and a plan of intermediate products achievements, of orientation and executive tools of action etc. The Third subsystem presents the stages of internalization or transfer of the action to the mental plan. Galperin has introduced six successful stages of internalization as a fundamental base of any learning process: (1) Stage of formation of motivation base of action. (2) Stage of formation of orientation base of action. (3) Stage of material (materialized) form of action. (4) Stage of external socialized verbal form of action. (5) Stage of internal verbal form of action. (6) Stage of mental action formation and final change, its automatization and simultaneouzation. The last, fourth subsystem contains a description of the three basic problem situation types as well as of their combination and presentation during formation processes: so called "psychological" type, in which conceptual and perceptual, visible features of problem situationare contraposed; "logical" type, in which necessary, essential and unnecessary, or "noiseful" parameters of problem situation are contrasted; and "object" type, in which all the possible forms of presentation of a specific action object content are varied. Different problem types are designed, regulated and presented to a learner in a definite manner and order (see: Galperin, 1989b), and produce combinations of problem situations. When three above mentioned sub-systems do "work" successfully and harmoniously, which ensures a desired and prescribed complete (from the point of view of accepted requirements), generalized (again, as much as it was planned), critical and conscious action's application in a prescribed field with a planned transfer, a learner analyzes them reasonably and meaningfully and solves them.

The procedure of "planned stage-by-stage formation of mental actions" (further - PSFMA) (Galperin, 1992b) in the most general form can be presented as follows. At the first stage the subject's initial attitudes toward the goals and objectives of the forthcoming process as well as toward the concrete learning/teaching situation are constituted; of course, those attitudes may be changed during the formation process. At the second stage the scheme of orienting (orientation) basis of action is elaborated; guided by a multilevel system of cues, marks and signs, a subject constructs, explores, reflects and performs the action being formed. The 
extent of autonomy of the subject to construct such a scheme may vary from a full dependence on a teacher to an almost full independence; it is the function of aims and goals of the concrete learning/teaching process and of the learner's characteristics. There should be ensured a harmonization of values, meanings, goals and executive learner orientation's; in the opposite case a whole set of negative consequences are expected either during formation process or after it when a new-formed action will come into existence (Podolskij, 1989; 1991; 1997).

The general macrostructure of this scheme is relatively indifferent to the features of the action's special domain content and to the level of expertise of the actor. The differences appear as soon as one compares concrete specifications of each element of the concrete orientation schemes in the actions of beginners and experts; of disabled, ordinary, and gifted children and so on. The macrostructure is also relatively indifferent to kinds and sorts of actions to be formed: whether they are concrete specific domain actions, or belong to cognitive metastrategies; or underlay the heuristically methods, etc. The general function of the scheme is to provide the learner with a powerful orientation means, or tool, which enables him to plan, to direct and to control the solving of different kind of problems related to the field involved (see above concerning the fourth sub-system of conditions). It should be emphasized that in general such a scheme is not an "algorithm" for solution (although in some cases and under definite conditions, few learners really need some kinds of "algorithmic prescription"; but it is an exception rather than a rule). This scheme is a real learner's tool for his/her orientation both in the objective content of action and in the operations needed to handle this content in accordance with concrete teaching-learning aims and goals. The process of its construction may become a real creative task for both (or few) participants of learning/ teaching interaction - for student(s) as well as for teacher(s). It is very important to stress that this scheme plays the role of a "synchronizator" for the development of knowledge and skills (see: Dijkstra, 1997) related to the content of the action. The scheme contains a necessary and essential information base both for learner's analysis of the action's objective content and for the application of this content to the definite problem situation.

At the third stage the learner starts to solve different tasks, organized and presented in the definite sequence and manner (see the fourth subsystem above), using the scheme of orientation basis of action elaborated on the previous stage. The form of the scheme may vary from detailed descriptions of an order and a content of operations to be executed to very general hints and heuristics. As for the external view of the scheme, it may be a scheme in a proper sense, or a "solution tree", or a text, or a picture. The representation is dependent on three variables just mentioned above: the objective content of the action, the learning goals, and the learner's characteristics.

The constancy of the action's essential structure, enforced by verbally reasoned solving of the sequence of specially designed (see above) problem types, leads to the point that it is no longer necessary for the student to use the scheme as the material learning aid. At that time its main content (see above - the second subsystem) is fully represented in the subject's socialized (that is understandable for other persons) speech. It becomes the base for the new action to be formed.

Thus the action moves into the fourth stage of formation - the level of overt socialized speech. Once the the set of varying problem situations has been solved, the so-called "melting" of the external phonetic form of speech takes place. It is the main content of the functionally intermediate fifth stage of action formation: formation of action's internal verbal mode. Accordingly, at the last, sixth stage of formation the mental action passes through final changes: simultanization and automatisation. The new mental action begins its own "psychological life". It becomes able either to be included in other psychological structures enriching them or to subsume other psychological structures to be enriched and developed.

Thus, as a result of stage-by-stage formation an externally mediated and successive action appears to be transformed into a "pure mental act": after estimating the problem situation a learner takes a decision on the spot. The results of planned stage-by-stage formation closely correspond with the most desirable aims of the contemporary Instructional Design: acquirement of generalized, meaningful, synchronized knowledge and cognitive skills is a result of authentic student's learning activity transformations.

To describe the frames of this approach generally in terms accepted by contemporary instructional design scholars, one may say that (a) instructional content is presented as a set or a system of interconnected actions, concepts and representations planned to be formed; (b) goals 
of instruction are defined and specified in terms of action parameters; (c) instructional plans were elaborated as didactic projections of stages of formation; (d) learners' characteristics are first considered in terms of the students' motivational and cognitive readiness to acquire projected mental actions and concepts.

The geterogeneous structure of a real learner's orientation in the action problem field, in the experimental (or learning/teaching) situation in general, and the non-linear character of an action's orientation formation preclude speaking about application of any constant, or, so to speak, "absolute" planned stage-by-stage procedure. The sequence of stages, the general structure of the orienting base of action and other "cornerstone" elements of system should be considered as the most complete, normative, and, according to Galperin, the nomothetic description of human mental action formation process (Galperin, 1992b). While considering empirical evidencies it is very hard to discover all the elements of this system. Thus some of the elements of PSFMA either appear from case to case or seem to be absent at all. However, while meeting a new problem situation a person has to construct what Galperin has called "orientation basis of action". In reality it may be done with different extent of generalization, consciousness, with this or that teacher's (parents', peers', etc.) participation and so on. Then a student starts (immediately or later, reasonably and consciously or not) to apply this base (scheme, mental plan or whatever) to a set of more or less varying problem situations (ideal or practical), which may have a chance nature or may be specially designed, with some extent of assistance of adults (peers). During an application of the orientation scheme one or another extent of generalization, reflectivity (criticism) etc. is acquired; a content of a learner's orientation basis is either confirmed or rejected and partially or fully replaced. One may continue such a quasi-empirical description as long as possible, but it will not influence the simple evidence that such an empirical (quasi-empirical) description is no more than a particular variant (one from infinite multitude) of the nomothetic description has been worked out by Galperin. And while it is possible to get in fact any empirical variant by "subtracting" of definite conditions from nomothetically described and psychologically complete system (of course, "complete" relative to our recent level of knowledge), an opposite way is principally impossible.
Stressing a nomothetically orienting role of the general scheme of PSFMA one implies that a successful application of the statements of PSFMA does not mean a literal replication of some abstract general procedure, but a creative design of a system of necessary and sufficient psychological conditions adapted to a concrete schooling situation. The elaboration of such a procedure occupies an intermediate position between the fundamental psychological knowledge and the real process of schooling, concrete schooling situation (Podolskij, 1993; 1997). Hence, the case in point is the elaboration of such a procedure occupying an intermediate position between the fundamental psychological knowledge and the real process of schooling, instructing, or training which could make it possible to take into account and to link, on the one hand, the general laws and regularities of formation of learners' mental activities as the nuclear part of any learning/teaching process and, on the other, the concrete individual- and social-psychological characteristics of learners as well as concrete characteristics of practical schooling situation.

This intermediate "application" position is operationalized in the consecutive elaboration of three models of the instructional situation: the psychological, the psychological-pedagogical and the methodical, or technological model (Podolskij, 1993; 1997).

The psychological model includes: (1) a description of knowledge and skills to be acquired as a set (a system if possible) in terms of the learners' mental actions and concepts; (2) a description of macro- and microstructure of the multilevel learner's orientation as the basis for a new mental action to be formed; (3) a description of age-related and individual characteristics of students that are relevant to the concrete situation of schooling; (4) a project of the system of psychological conditions needed for the formation of the planned actions. It is clear that in different applications of the PSFMA system, the emphasis should be placed on different constituents of the psychological model.

The main function of psychological-pedagogical model is the projection of psychological model demands onto the concrete objective and subjective conditions of school teaching: instructional activities and organization and distribution of different organizational forms during a lesson or a sequence of lessons; a quantity of in-class and homework activities; amount of individual, small group and whole class learning activities; use of available technical aids of teach- 
ing (including computers when necessary) and their desired facilities, etc. It is only while constructing this model when the questions concerning preservation or change of the form of conducting classes, expedience of dividing them into traditional "explanation", "practice" and "control", distribution of functions between teacher, technical aids and students to ensure an acquisition of new knowledge and skills, and so on first arise. It is perfectly clear that a successive following the PSFMA psychological model requirements influences radically all the components of learning and teaching activities. This is why the question of the high priority should be exclusively concrete: what is more expedient from the actual and prospective point of view: the radical restructuring of the learning/teaching process with the almost guaranteed sharp increase of its efficiency, or preservation (of course, only in general), or thorough partial revision of its content and possible forms with losses of some psychological model demands, which, accordingly, produces a smaller effect. A special and a very interesting question is about the "information base" of such a decision. School head-master (rector, director) plays, as a rule, a role of "decision maker". Our experience shows that to make such a decision means to evaluate actual professional values and motives of teachers involved in schooling innovation process, as well as their expertednesses, to estimate their strong and weak sides, to ensure teachers' accepting, understanding, willing and practical experiencing towards planned instructional innovations. It is impossible to abstract oneself from the heterogeneous and psychologically multilevel question of teachers' competence while solving real practical ID problem.

The last, methodical, or technological model of instructional situations includes a detailed description of the teaching process, distributed between units of definite form and time, with a precise description of the goal of each unit and the means to achieve it. It also includes a complete list of methodological teaching documentation: schemes, different kinds and types of learning and assessment tasks, descriptions of the order in which technical aids should be applied, and a number of other materials specified for different types and kinds of schooling/instructional situations. The methodical model looks like traditional well-done "teacher's lesson plan"; but one has to remember that such inventarization is going along the channel outlined by the psychological as well as psychological-pedagogical models.
Considering three-model scheme we deal with an intellectual tool again. It is not an algorythm which prescribes "how to act". Used in an appropriate and sophisticated way, this framework gives a designer and a teacher a chance to orient, to plan, to control him/herself completely, and correctly design, arrange and perform different instructional activities.

As far as the presented approach is a tool for a teacher's (designer's) thinking rather than a prescription for a specific teacher activity, it is a difficult task to give one or two examples which would comprehensively illustrate both the PSFMA procedure as a whole and all its elements. Different learner characteristics, subject matter contents and learning / teaching goals highlight one group of subsystems and their elements and shadow the other group.

Two examples are presented at the end of this paper to give an idea how this tool works when it succeeds and when it fails. At first, the case of formation of attentiveness in two different groups of young schoolchildren will be considered. The problem (both scientific and practical) is that young schoolchildren rather often demonstrate a lack of attentiveness (or, attention) performing a learning activity. They miss or invert letters and syllables when writing, add figures when a subtraction sign is in the arithmetic task, they are not able to find the differences between two compared pictures, etc. At the same time the learners who suffer from inattentiveness are, as a rule, quite successful in the knowing and applying the appropriate rules (linguistical, mathematic, etc.) which regulate proper execution of tasks. To apply the PSFMA-oriented approach to schooling means, as mentioned before, is to describe knowledge and skills to be taught as the learner's mental actions which have to be formed under conditions of the appropriate learning environment. Galperin supposed that a mental action of checking, as a necessary and essential part of human control activity, represents the main psychological content of the learner's attention (attentiveness). Both attentiveness (attention) and checking never function as independent processes and have no discrete, specific product of its own. The result is an improvement in any activities to which they are linked (Galperin, 1989c). Hence to get the positive changes in attentiveness means to ensure: (a) an adequate students' motivation to acquire checking competence; (b) working out a scheme of orientation basis of the checking action; (c) an internalization of the initially 
Table 1

Number of mistakes related to inattentiveness (in average for one task)

before and after planned stage-by-stage formation of checking action in 10-year old children; $(n=230)$ (by Podolskij, 1997)

\begin{tabular}{lcc}
\hline \multicolumn{1}{c}{ Task } & Before formation & After formation \\
\hline To copy a correctly written text & 4.1 & 0.1 \\
To correct mistakes in a text & 3.8 & 0.1 \\
To correct a text using an example & 2.7 & 0.0 \\
To write a dictation & 5.5 & 0.4 \\
Simultaneously to copy and cor- & 4.4 & 0.2 \\
rect a text containing mistakes & & \\
\hline
\end{tabular}

external checking action; and, (d) acquisition of the desired properties by the action formed.

Many studies were conducted (see, for instance, Galperin, 1989c; Podolskij, 1997) where the subjects were third-, fourth-, or fifth-graders distinguished for having many mistakes on account of inattentiveness. An adequate motivation was ensured by means of the demonstration how inattentiveness deteriorates the final learners' products: written texts, math task solutions etc. A scheme of the orienting basis of checking action has being introduced as a result of a group discussion with the children concerning the problem: What to do to overcome the inattentiveness. Being collectively worked out under the teacher's guidance, this scheme represented a set of connected rules what was to be checked and how it should be done. Each student had a chart with the scheme that was to be used to solve different tasks when copying a correctly written text, copying and checking a text with deliberately made mistakes, writing a dictation with checking and correcting one's own mistakes both after writing and simultaneously with writing etc. While solving a variety of checking tasks (see above - the fourth subsystem of the planned formation of mental actions) the students changed (certainly, under the carefully planned teacher's guidance) the form of their performance. Initially external, or materialized form, when the learners solved the tasks using a visually presented content of the chart, was replaced by the next forms of internalized checking action (see above - the third
Table 2

Number of mistakes related to inattentiveness (in average for one task)

before and after planned stage-by-stage formation of checking action

in 11-12-year old children with compensated speech disorders $(n=89)$. The ordinary PSFMA procedure (by Podolskij, 1997)

\begin{tabular}{lcc}
\hline \multicolumn{1}{c}{ Task } & Before formation & After formation \\
\hline To copy a correctly written text & 7.2 & 1.0 \\
To correct mistakes in a text & 7.3 & 0.7 \\
To correct a text using an example & 3.3 & 0.7 \\
To write a dictation & 5.0 & $\mathbf{6 . 0}$ \\
Simultaneously to copy and cor- & 2.4 & $\mathbf{3 . 8}$ \\
rect a text containing mistakes & & \\
\hline
\end{tabular}

subsystem of PSFMA conditions), and was finished by an ideal form of checking activity. At the final stage the student executed the main activity (writing, solving math tasks etc.) and simultaneously checked whether there were errors in his or her work. As Table 1 shows, initially inattentive children became attentive (at least, in the limits tested). Errors related to inattentiveness practically disappeared from their school notebooks.

The same forming procedure has been performed with other subjects. The subjects were 11-12-year old children with well compensated speech disorders from which they had suffered in early childhood and from which they had been successfully cured (see Table 2).

As Table 2 shows, solutions of only the first three tasks became essentially better after formation. The last two tasks which presupposed not only an execution of a formed action but also its involvement into the structure of the main (in this case, writing) activity demonstrated a paradoxical decrease in the results after formation. A special analysis was executed. It discovered that the students were not able to involve independently the new competence into a real learning activity. The students could not form a content of action with their real learning activity, did not see a personal meaning, or a sense why and for what it is necessary to become competent in checking. They used to follow their teachers' demands. While participating in formative procedure they simply followed the cues of the chart given to them by a teacher 
Table 3

Number of mistakes related to inattentiveness (in average for one task) before and after planned stage-by-stage formation of checking action

in 11-12-year old children with compensated speech disorders $(n=67)$. Revised PSFMA procedure (by Podolskij, 1997)

\begin{tabular}{lcc}
\hline \multicolumn{1}{c}{ Task } & Before formation & After formation \\
\hline To copy a correctly written text & 7.0 & 0.5 \\
To correct mistakes in a text & 7.0 & 1.0 \\
To correct a text using an example & 3.7 & 0.0 \\
To write a dictation & 7.8 & $\mathbf{0 . 3}$ \\
Simultaneously to copy and correct & 5.8 & $\mathbf{0 . 7}$ \\
a text containing mistakes & & \\
\hline
\end{tabular}

(it turned out to be impossible to work out a content of the scheme of orientation basis of action with those students in the same manner as it was done with the first group described above). It caused the results given in Table 2.

To overcome the difficulties a special game procedure was elaborated to provide the next group of students (with the same anamnesis as the previous one) with a harmonization of their orientation structure (Podolskij, 1989). For the learners that game opened the links between a sense (personal meaning) of a checking activity, goals generated by a subject while learning activity performing, and executions of concrete checking actions. All the attributes of PSFMA were applied to that additional formation procedure. The object of formation was not the action execution (as it was in the first case with ordinary schoolchildren) but rather a hierarchical structure of an above-executive orientation. The following results were achieved after performing the modernized procedure (see Table 3).

This case demonstrates that a literal reproduction of a PSFMA procedure (even if it was very successful beforehand) doesn't work. It should be preceded by a careful psychological analysis covering all the appropriate learner and subject matter content characteristics. Only after making such analysis it becomes possible to work out teaching materials and procedures.
The second case is absolutely different and does not belong to the traditional areas where the PSFMA approach used to be applied such as preschool and primary school education, vocational training, etc.

Fast and radical social-economic changes in the postcommunist countries in 1990s produced a sharp need to change professional orientation, professional and vocational training and retraining, or, broader, the practices of lifelong learning. Indeed there is a necessity to reconstruct not only professional knowledge and skills but rather attitudes towards life and work in general.

First attempts to assess the reorientation and retraining procedures under such conditions showed that a complex set of heterogeneous factors influenced the efficiency of those procedures. At the same time it revealed how difficult it was to directly transfer schemes, principles and approaches used in Western Europe (Terlouw, Podolskij, et al., 1997). One reason is that strong social-economic changes are accompanied by no less strong psychological changes, particularly, negative emotional states (depressive mood, anxiety, etc.) in various groups of population. It appeared that to deal with the problem you need to be able to simultaneously take into account a lot of different parameters and factors such as social, cultural, economic, psychological, psychophysiological, and medical ones both on the design and implementation phase. To succeed in such a task one has to have an adequate knowledge base to grasp all the plurality and complexity of the multilevel psycho-educational mechanisms, which influence the efficiency of such teaching and learning. We had a firm belief that the neo-Galperinian approach based on three-model system may play a role of a proper intellectual tool to design and implement such a retraining procedure.

Taking into account the specificity of both the social-economic situation in the countries with transition economy and its hard psychological consequences, it was supposed that such a knowledge base may consist of the following three parts: 1) hierarchical model of human orientation in learning/training situation (Podolskij, 1997); 2) age-related and functional developmental model of adult learning under conditions of radical social-economic changes (Podolskij, Idobaeva, 1999); and 3) multilevel implementation model adequate to the analyzed situation (Terlouw, 1993; Podolskij, 1993).

The case of reorientation and retraining of a group of higher educated unemployed women from Obninsk (a town near Kaluga, Russia) 
during the course of starting business is the core of the second example of the discussed approach application.

The object of design in the case is complex and multilevel. Although the final goal of the course design and the implementation of the course seem to be quite traditional - to retrain people from military industry for new (actual or potential) peaceful occupations due to progressing unemployment processes - it is only the top of the iceberg. To be successful and productive the course design product has to be sensitive, among other things, to the specificity of instructional-learning processes. Terlouw (1995) considers this level as the operational one.

Designing and planning such a course one has to take into account the parameters of management and administration of the instructionallearning processes as such (tactical level according to Terlouw) and even the concrete characteristics of the social policy of local and regional authorities (strategic level).

\section{Retraining unemployed women with higher}

\section{education as a case of the GIT application}

Thirty 30-45-year old women with higher education and a relatively long professional experience in engineering or management and from 3 to 12 months of unemployment took part in the training course as students. All the essential statements pointed out in contemporary literature concerning adult learning and instruction was completely applicable and suitable for them. They did demonstrate an active and constructive character of learning processes; their mental models have clearly discovered well-known types of knowledge representations; the students were undoubtedly self-directed learners who actively participated in creating learning environments. Age- and sex-related characteristics were also completely present as well as individual-psychological ones. At the same time few essential characteristics existed as well. The first feature was directly related to the students' educational level. As all of the students were higher-educated people, their occupational aspirations, self-reflections and expectations did not correspond with the real local and regional placement possibilities. There were $75 \%$ of women among unemployed people in Obninsk city at the beginning of the study in $1995.58 \%$ of unemployed women were higher educated. Only $12 \%$ of existing vacancies were for higher-educated people and no more than $7 \%$ of them were for women. It meant that less than $1 \%$ of total amount of vacancies were for higher-educated women who in fact formed $42,5 \%$ of all unemployed people.

The second feature was a strong and very stable emotional tension that characterized almost all the participants of the study. Many of them were withdrawn from professional, social, and civil life. Long-term impossibility to get a working position adequate to their professional qualification and competence provoked aggression and conflicts in interpersonal relations both in community and in family. The same reason also caused increase of personal anxiety and depressiveness.

The third feature regarded to the specific social-economic situation in Russia and in Kaluga region in particular: besides the usual and general difficulties for all the countries in the world starting entrepreneurs met, the Russian beginners faced some additional serious problems, such as: an absolutely unreasonable state and regional taxation, which did not stimulate but, on the contrary, prohibited an entrepreneur initiative, a permanent risk to be attacked by criminals, unpredictability of the market development and other things caused by a social and economic instability of Russia. However, although our students were the persons with a high level of general and special intellectual abilities and rich real life experience as well, they nevertheless had illusions about their exclusiveness among other actors on the current stage of the dramatic Russian history.

It was quite clear that those students' characteristics had to influence significantly the forms and manners of the training course's design and execution. Firstly, for almost all the students it was practically impossible to start the training procedure without initial relaxation procedure designed and organized on the base of the preliminary investigation of the individual psychophysiological, somatic, emotional and personal status. Secondly, as preliminary analysis showed, the most serious obstacle to find a proper solution in a new employment situation was students' intellectual and motivational rigidity, reluctance and impossibility to look for non-stereotype, creative solutions, especially concerning their own personal and professional potential. The task was to help the students to re-aware their values, meanings and goals regarding the newly formed orientation in the replacement situation, and more broadly - in the situation of self-realization (see: Podolskij, 1993; 1997). Thirdly, it appeared necessary to demonstrate as bright and unambiguous as possible the links between the real life difficulties of the 
students and concrete and realistic programmes to overcome those difficulties (to materilize, Galperin, 1989c). Taking into account a high intellectual potential and simultaneously negative emotional state of the mind of the students such a demonstration had to be done very convincingly. Fourthly, it was possible to speak about the positive results of the training (especially looking ahead) only in case the final product, satisfactory placements of the students, was achieved.

\section{The training process}

The curriculum designed had the following parts that corresponded to the stages of the training procedure: Preliminary stage. Psychological and psychophysiological investigation made by a psychologist and/or a medical doctor. Entrance control. Pre-tests. First stage. Psychological relaxation. Psychophysiological self-regulation training. Main target: to create a positive emotional background in the students. Second stage Individual work with the students. Analysis of the internal and external situation - what had changed inside and outside the students while they were unemployed? Individual consultations based on the results of the psychological pre-tests. Discussion of the student's goals, plans, and intentions. Clarification of the main problem of each student. Analysis of the realistic and unrealistic, constructive and destructive approaches to resolve the problem(s). The main target was to form adequate motivation in the students to acquire abilities and competencies which were initially absent. Third stage. Group work. Social-psychological training, video training, brain storming, case analysis, simulation of real life problem situations, training of self-organization in problem-solving. The main target was to arouse the students' creative life energy, to overcome thinking stereotypes. Fourth stage. Formation of the student's general occupational intention: concrete, realistic, locally or regionally approved. Creation of the package of the starting entrepreneur's documents such as market analysis, business plan, financial plan etc. The main target was professional self-orientation and self-realization. Fifth stage. Post-tests. Exit control. Sixth stage. Analysis of the students' successes in their trials to get job after training course.

\section{Results}

The whole procedure took two months. It was a relatively short period of time as compared with the similar experiences in Western Euro-
Table 4

Anxiety and depressive mood before and after training procedure (measured by Khanin-Spielberger scale) Amount of cases, general N = 30

\begin{tabular}{ccccccc} 
& HPA & HRA & HPaRA & ELA & SDS & RDS \\
\hline PRE-TEST & 12 & 7 & 5 & 2 & 3 & 1 \\
POST-TEST & 7 & 2 & 0 & 0 & 0 & 0 \\
\hline
\end{tabular}

Legend: HPA - high personal anxiety; HRA - high reactive anxiety; HPaRA - high personal and reactive anxiety; ELA - extra low anxiety; SDS - sub-depressive state; RDS - real depressive state.

pean countries; we believe the difference is due to the high educational level of our students. We consider that the results in the following domains were achieved: (1) Actual student's placement; (2) psychological indicators; (3) behavioural indicators.

(1) The main objective indicator of the described procedure efficiency was, of course, the amount of our students who were able to employ themselves after the course. The acquired competence to analyze a life problem situation constructively helped 22 students out of 30 to find a satisfactory working place. Six students decided to start their own enterprise alone or together with friends, relatives or former colleagues. Two students decided not to seek a job. On the basis of the new knowledge and acquired skills they saw a possibility to self-fulfilment in family life.

(2) We conducted a set of pre- and post tests to estimate a psychological efficiency of the training procedure. As mentioned above, one of the most demonstrative psychological indicators that accompany radical social-economic changes in Russia is the appearance of negative emotional states (depressive mood, anxiety, etc.) of different groups of population. Accordingly, a decrease in that indicator would demonstrate positive trends in the target group's psychological welfare. Table 4 demonstrates a decrease of students' anxiety as a result of the training procedure.

(3) Besides the dynamics of emotional states we also registered the dynamics of students' behaviour and changes in how they looked. We did it analyzing videotapes recorded during all the sessions. It was amazing to watch that all the women started to pay more attention to their appearance from session to session. The very first video records showed how tense and 
nervous the students were, their careless style of dressing and make-up, the last records demonstrated an absence of external signs of tension and anxiety; most ladies looked well and dressed almost as for a party. Many students became friends, often met outside of training sessions to discuss mutual problems and to back those who still were in a heavy mood. All students were asked at the last session: "Did group training work influence you? If yes, in which way?" The following answers were given:

- Self-confidence appeared;

- I started to believe in my own abilities;

- I got a feeling of independence;

- I realized that I am able to work not only within my speciality;

- I found a lot of new in myself, became more self-confident;

- I overcame a feeling of anxiety and hopelessness;

- I became more open in contacts with other people;

- I'm not afraid of the future any more as I learned how to deal with my problems.

Thus, with the use of the complex and systemic (although heterogeneous) psychological knowledge base that contained: 1) hierarchical model of human orientation basis in a situation of learning (Podolskij, 1991); 2) age-related and functional developmental model of the adult learning under the conditions of radical social-economic changes (Podolskij, Idobaeva, 1999); and 3) multilevel implementation models adequate to the analyzed situation (Terlouw, 1993; Podolskij, 1993; 1994; 1997), we designed and organized the practices of a system of necessary and sufficient psychological conditions: (a) to form and develop a heterogeneous student orientation basis in the internal (psychological) and external (social-economic) situations (one important element of the hierarchy not mentioned in the literature before is a positive psychophysiological status of the students; another important element of the hierarchy which belongs to its higher levels is an internal personal trust in the information given and, accordingly, knowledge acquired);

(b) to ensure a stage-by-stage transition (internalization by Galperin) of initially materialized external students' orientation basis to the mental level (different forms of schematization, discussion, problem solving were used); (c) to provide students with an opportunity to apply knowledge and skills acquired during the course to deal successfully with their real life problems.
It is important to stress that our students really created their new knowledge and skills in the training. They did it naturally in close collaboration with a teacher and with each other. They didn't play a role of "pupils" and only sometimes were "apprentices". A few parts of the training were organized as a collaboration of the specialists (psychologists, local authorities, entrepreneurs etc.) and the students. Such a manner of conducting practical classes was accepted and appreciated by the students.

\section{Conclusion}

It seems to be highly doubtful both practically and theoretically to try to prescribe a teacher, or a trainer to do something, "to prescribe" in a proper and exact meaning of the word. What psychology can and must prescribe are the definite directions, marks and "milestones" for teacher's (trainer's) thinking. The most important thing the modern psychological and educational science might give a teacher is a general intellectual tool that may be used not in order to prescribe a designer's or teacher's executive activity but rather to give them an extended and sophisticated approach to the processes and events, which constitute the student's learning and the teacher's instructional activity. Designers and teachers have to be provided with the knowledge about all the complexity of the psychological mechanisms which underlie learning/teaching processes and with the knowledge how to "switch on" these mechanisms by means of creating and using a system of necessary and sufficient conditions.

A possible approach, based on the Galperin's psychological doctrine, especially on his "Planned stage-by-stage formation of mental actions" theory, has been described. This approach gives a general outlook on different processes that underlie mental actions and concepts acquisition. It is based, on one hand, on the theoretical analysis of a human mental life nature, and, on the other hand, on the carefully elaborated and tested system of psychological conditions of the planned formation of mental actions and concepts with definite properties. This system is sensitive not only to the functional and structural characteristics of schooling and instructional processes and products, but also to the age-related, and functional developmental variables. Being experienced in the use of this system, one may, in fact, describe any newly-formed mental structure 
acquisition in concrete and operationalized terms. Being supplemented by a three-model scheme that bridges a gap between psychologically described conditions and a variety of real schooling circumstances, this system gives a teacher a chance to predict the most probable developments both in the realization of the definite teaching/learning process and in the characteristics of the products of this process.

\section{References}

Dijkstra, S. (1997). Models and plans to solve instructional design problems. In S.Dijkstra et al. (eds.). Instructional design: International perspectives, 2. Mahwah: Lawrence Erlbaum Associates.

Galperin, P.Ia. (1967). On the notion of internalization. Soviet Psychology, 5, 3. P. 28-33.

Galperin, P.Ia. (1982). Intellectual capabilities among older preschool children: On the problem of training and mental development. In W.W.Hartup (ed.). Review of child development research, 6. Chicago: University of Chicago Press. P.526-46.

Galperin, P.Ia. (1989a). Organization of mental activity and effectiveness of learning. Soviet Psychology, 27, 3. P. 65-82.

Galperin, P.Ia. (1989b). Study of the intellectual development of the child. Soviet Psychology, 27, 3. P. 26-44.

Galperin, P.Ia. (1989c). The problem of attention. Soviet Psychology, 27, 3. P. 83-92.

Galperin, P.Ia. (1992a). The problem of activity in Soviet Psychology. Journal of Russian and East European Psychology, 30, 4. P. 37-59.

Galperin, P.Ia. (1992b). Stage-by-stage formation as a method of psychological investigation. Journal of Russian and East European Psychology, 30, 4. P. 60-80.

Podolskij, A.I. (1989). Internalization of action: scientific abstraction and reality. Paper presented as Invited Address at 10th Biennial Meetings of the ISSBD. July 9-13. Juvaskyla.

Podolskij, A.I. (1991). New life of old idea: process of internalization as we see it in learning experiments and instructional practice. Paper presented as Invited Address at 4th EARLI Meeting. August 24-29. Turku.

Podolskij, A.I. (1993). Psycohological theory as base of instructional design and as part of curriculum in post-graduate education. In C. Terlouw (ed.). Instructional developement in higher education: theory and practice. Amsterdam: Thesis Publishers.

Podolskij, A.I. (1994). Bridging the gap between development and learning studies: the concept of developmental tasks. In J. ter Laak, Peter Heymans \& A.Podolskij (eds.). Developmental Tasks: Towards a cultural analysis of human development. Kluwer Academic Publishers.
Podolskij, A.I. (1997). Instructional design for schooling: Developmental issues. In S. Dijkstra, et al. (eds.). Instructional Design: International Perspectives, 2. Lawrence: Erlbaum.

Podolskij, A.I., and Idobaeva, O.A. (1999). On psychological knowledge base for life long learning under conditions of radical social-economic changes. Life Long Learning in Europe, 1. P. 31-40

Talyzina, N. (1987). Pedagogicheskaya psichlogiya [The Psychology of Learning]. Moskva.

Terlouw, C. (1993). A model for instructional development: integration of theory and practice. In C. Terlouw (ed.). Instructional development in higher education: theory and practice. Thesis Publishers, Amsterdam.

Terlouw, C., Podolskij, A., Eterman, E., and Plotnikova, Yu. (1997). Evaluation and re-design of employment education for demobilized officers in Russia. Lifelong Learning in Europe, 2. P. 29 - 37.

Vygotsky, L.S. (1978). Mind in Society. Cambridge, MA: Harvard University Press. 